\title{
TRATAMENTO DA TINEA PEDIS COM MICONAZOLE EM PACIENTES DE AMBULATÓRIO
}

\author{
NOTA PREVIA
}

\author{
J. Martins de BARROS * \\ Walter BELDA *
}

\section{RSPSP-143}

Barros, J. M. DE \& Belda, W. - Tratamento da Tinea pedis com Miconazole em pacientes de ambulatório. Rev. Saúde públ., S. Paulo, 6: 287-92, 1972.

Resumo: Vinte e seis portadores de Tinea pedis foram tratados durante 4 semanas, duas a três vezes por dia, com aplicaçōes de Miconazole sob forma de po, loção ou creme, isolados ou associados. Em 23 casos $(88 \%)$, as lesões methoraram ou desapareceram, num perio. do de 2 a 4 semanas.

Unitermos: Tinea pedis*; Terapeutica $^{* ;} ;$ Miconazole $*$;icoses.

$$
1 \text { - INTRODU ÇÃO }
$$

As micoses superficiais, embora com. prometendo apenas a camada epidérmica da pele e provocando lesões benignas, podem se tornar problema de interesse sanitário, não só pelo desconforto que acarretam ao doente, mas ainda pela frequiência elevada em alguns grupos da população. É o caso da tinha dos pés, cujas complicações produzem sofrimento, podem ser causa de absenteismo ao trabalho e de impedimento à prática de alguns esportes. Daí a importância de se ter à mão o maior número de medicamentos para combater esse mal.

O Miconazole é um derivado sintético de 1-fenetil-imidazol, e se aprasenta como pó branco cristalino, discretamente so. lúvel na água. É uma substância estável, que pode ser conservada inalterada durante vários meses, em condições normais de temperatura.

De acordo com experiências realizadas, o Miconazole demonstrou alta atividade contra fungos, dermatófitos e levedos, razão pela qual foi essa substância incluída na área de estudos da Disciplina de Dermatologia Sanitária da Faculdade de Saúde Pública da USP.

\section{MATERIAL E METODO DE ESTUDO}

Foi observado, em um primeiro estudo, um grupo de 26 pacientes todos de ambulatório e portadores de lesões de Tinea pedis. O medicamento foi usado sob forma de creme, solução e pó, isolada ou associada.

Os pacientes eram instruídos no sen. tido de aplicar uma pequena quantidade de loção ou creme nas lesões, duas a

(*) Da Disciplina de Dermatologia Sanitária da Faculdade de Saúde Pública da USP - Av. Dr. Arnaldo. 715 - São Paulo. S. P., Brasil. 
BARRos, J. M. de \& BELDA, W. - Tratamento da Tinea pedis com Miconazole em pacientes de ambulatório. Rev. Saude públ., S. Paulo, 6: 287.92, 1972.

três vezes ao dia, com as pontas dos dedos, esfregando até $O$ desaparecimento do medicamento pela absorção da pele. A aplicação era feita pela manhã e à noite, sendo permitido aos pacientes seguirem a rotina de higiene local mas não a utilização de outros medicamentos. Quando se associou o pó, era este polvilhado uma vez ao dia, pela manhã, em lugar de uma das aplicações da loção ou do creme.

De todos os pacientes foi colhido material para exame microscópico e cultura. O material era obtido por meio de raspagem das lesões. $O$ exame ao microscópio era feito após clareamento do material pela potassa a $30 \%$. A inoculação do material foi feita com agarSabouraud, para identificação.

Os pacientes eram seguidos semanalmente, durante 4 semanas pelo menos. Alguns pacientes foram seguidos durante 45 dias.

O critério de melhoria baseou-se na involução clínica das lesões e o de cura, no desaparecimento das mesmas; sendo que em grande parte dos casos, foram repetidos os exames microscópico e a cultura.

O Miconazole foi experimentado sob a forma de pó, creme e loção, nos se. guintes esquemas: $A=$ pó e loção; $B=$ loção; e $\mathbf{C}=$ pó e creme.

RESUITADOS

Os resultados foram divididos em: satisfatórios e não satisfatórios. Satisfatórios, quando houve desaparecimento do prurido e da irritação local, com desaparecimento ou melhoria acentuada das alterações da pele. Não satisfatórios, quando houve persistência do prurido, das irritações e alterações da pele.

Dos 8 pacientes que usaram o medi- camento sob forma associada de pó e loção, apenas em um caso as lesões não desapareceram em 30 dias, e foi considerado não satisfatório. Nos restantes 7 casos, a cura se deu entre 14 a 30 dias de tratamento.

Dos 8 pacientes que usaram o medicamento exclusivamente sob forma de loção, todos tiveram regressão das lesões entre o $14 .^{\circ}$ e $\circ 28 .^{\circ}$ dia de tratamento. Não houve casos suspeitos de intolerância ao medicamento.

Dos 10 pacientes tratados com esquema associado de pó e creme, em 8 casos as lesões desapareceram em um periodo médio de 25 dias e, em 2 casos, o tratamento teve que ser suspenso devido à exacerbação das lesões. $O$ prurido desapareceu, em média 3 dias após o tratamento, e, em um caso, o prurido exacerbou-se nos 2 primeiros dias de tratamento, para melhorar em seguida.

\section{CONCIUSOES}

Dos 26 pacientes tratados com Miconazole, apenas em um caso as lesōes não regrediram no fim da 4." semana de observação e, em 2 casos, houve necessidade de suspender 0 tratamento por exacerbação da sintomatologia local.

Nos demais 23 casos (88\%) as lesões melhoraram ou desapareceram num mínimo de 2 semanas e máximo de 4 semanas.

Tendo em vista que a grande maioria dos pacientes apresentava a moléstia há vários anos, com recidivas ou resistência a vários medicamentos, os resultados observados podem ser considerados satisfatórios.

Por outro lado, sendo o medicamento inodoro $\epsilon$ incolor e não produzindo irritação local, foi muito bem tolerado por 24 dos 26 pacientes. 
BARRos, J. M. de \& BELDA, W. - Tratamento da Tinea pedis com Miconazole em pacientes de ambulatório. Rev. Saúde públ., S. Paulo, 6: 287.92, 197\%.

\section{RSPSP-14?}

Barros. J. M. dE \& Belda. W. - [Treatment of Tinea pedis outpatientes with Miconazole 7 Rev. Saúde públ., S. Paulo, 6: 287-92, 1972.

Summary: Twenty six patients of Tinea pedis were treated with Miconazole 2-3 times a day. The drug was used as lotion, cream or powder in local applications. Lesions ameliorated or disappeared in 23 patients (88\%), within an average period of $2-4$ weeks.

UNITERMS: Tinea pedis*; Therapeutics*; Miconazole*; Mycosis.

\section{REFERENCIA BIBLIOGRAFICA}

BRUgMaNs, J. P. \& CUTSEN, J. M. - Avaliaçấo clínica pelo método duplo-cego do Miconazole no tratamento da Tinea pedis crônica. Arq. Dermatol. [no prelo].

Recebido para publicacão em 11-7.1972

Aprovado para publicação em 26-7.1972 
BARROS, J. M. de \& BELDA, W. - Tratamento da Tinea pedis com Miconazole em pacientes de ambulatório. Rev. Saúde públ., S. Paulo, 6: 287.92, 1972.

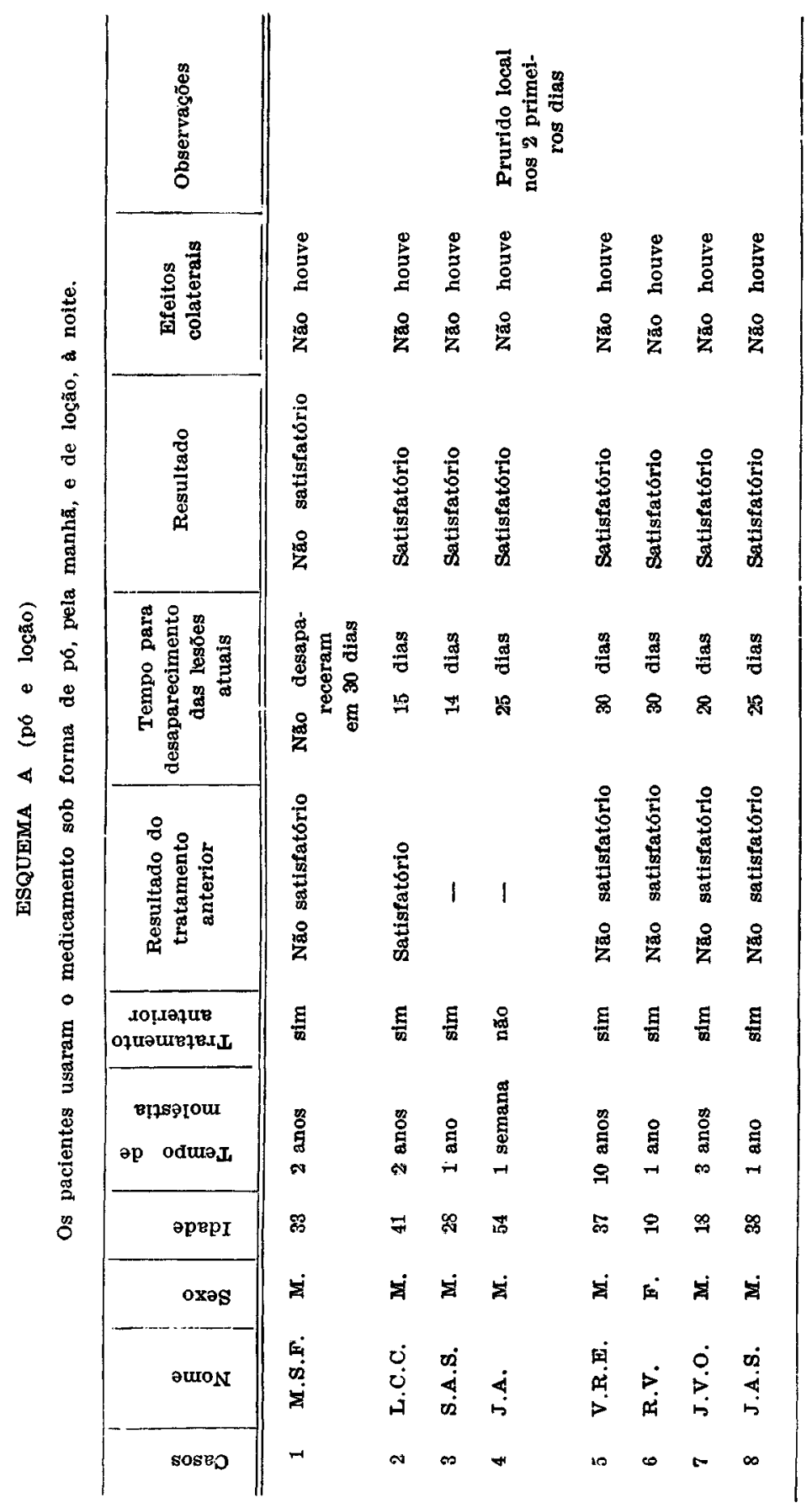


BARRos, J. M. de \& BELDA, W. - Tratamento da Tinea pedis com Miconazole em pacientes de ambulatório. Rev. Saúde públ., S. Paulo, 6: 287.92, 1972.

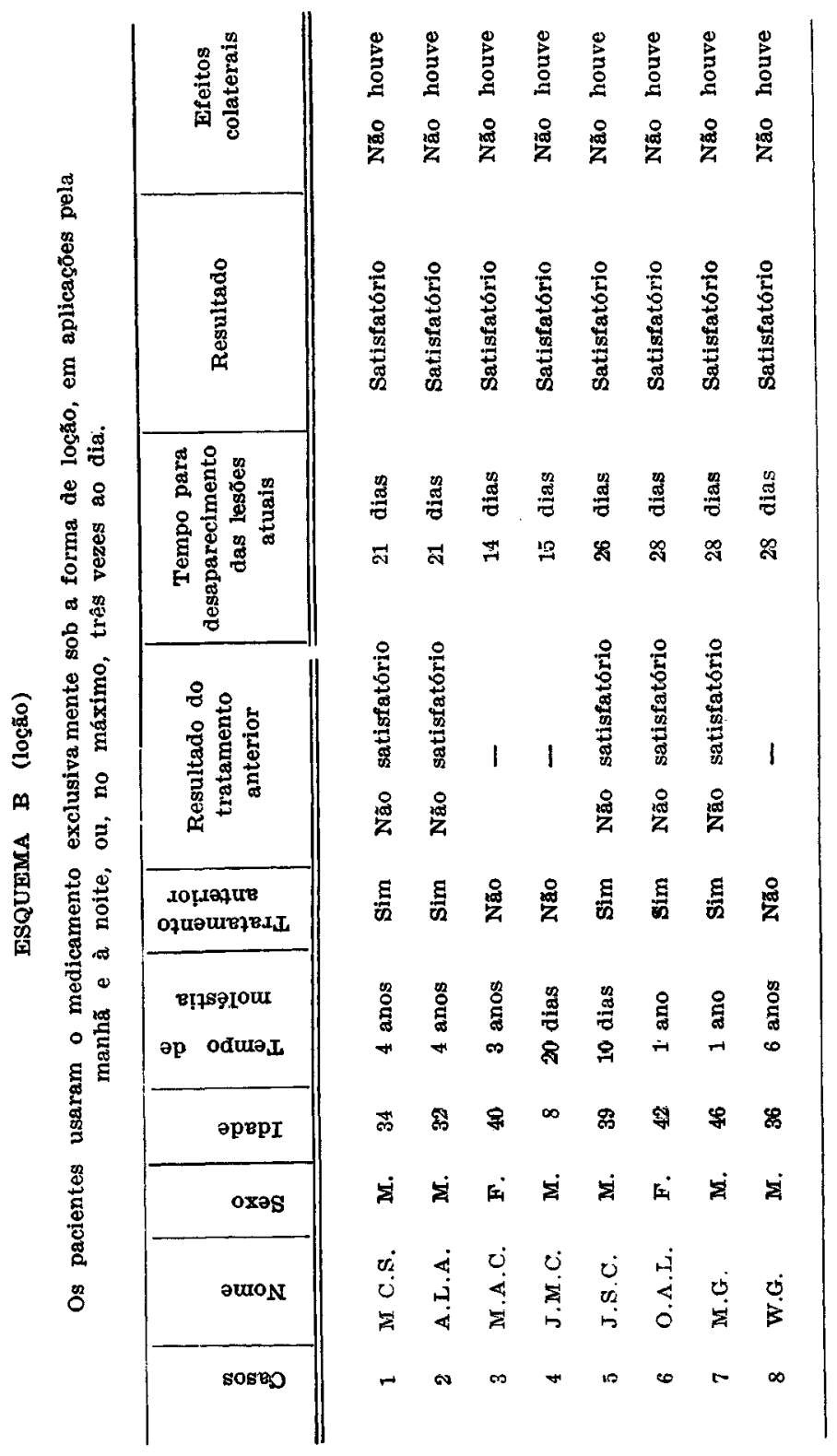


BARROS, J. M. de \& BELDA, W. - Tratamento da Tinea pedis com Miconazole em pacientes de ambulatório. Rev. Saúde públ., S. Paulo, 6: 287-92, 1972.

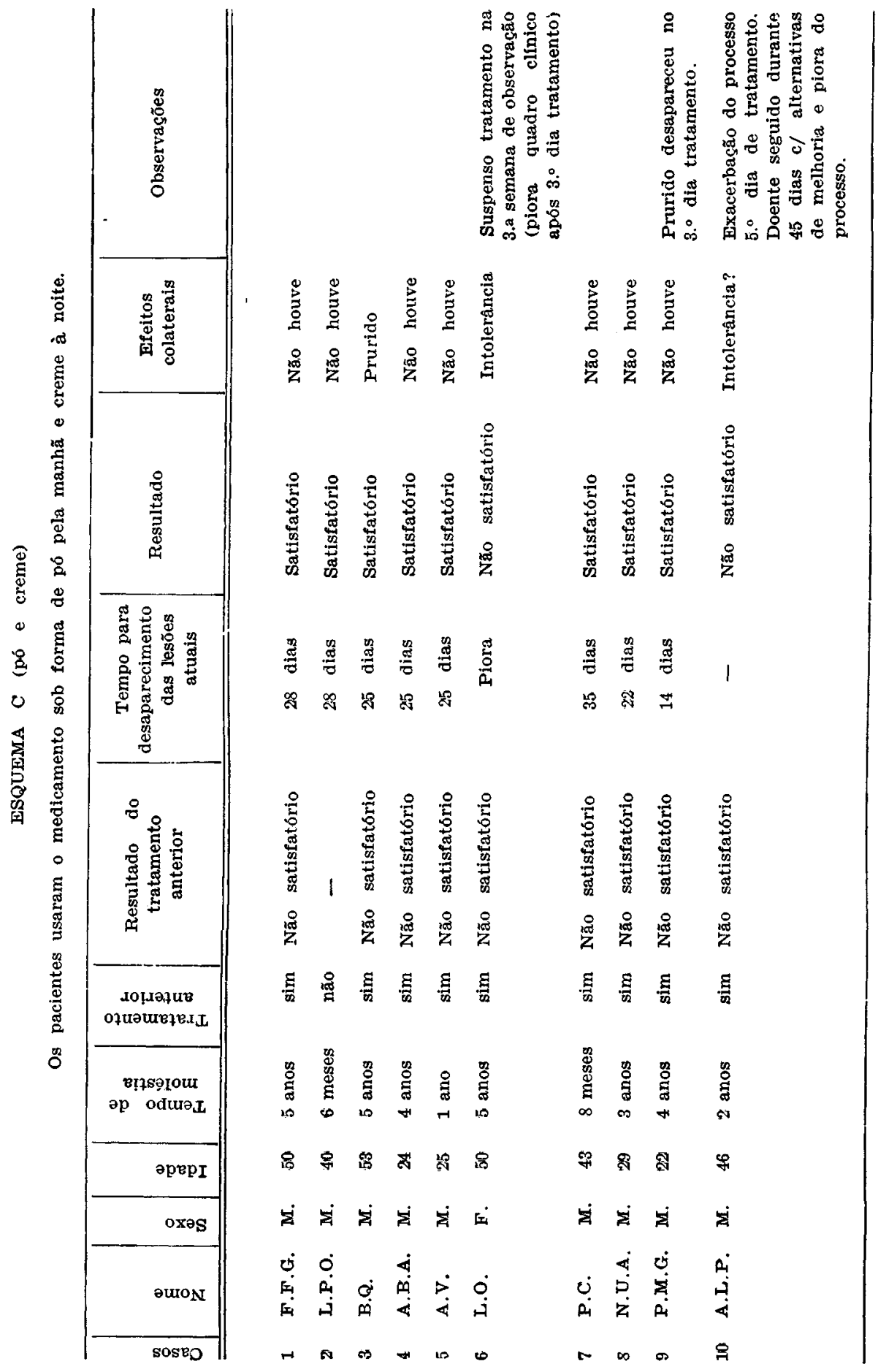

